\title{
Diastereoselective synthesis of novel aza-diketopiperazines via a domino cyclohydrocarbonylation/addition process $\dagger$
}

Cite this: Chem. Commun., 2014, 50,9657

Received 14th May 2014,

Accepted 3rd July 2014

DOI: $10.1039 / c 4 c c 03660 c$

www.rsc.org/chemcomm

\author{
Pierre Regenass, Jean-François Margathe, André Mann, Jean Suffert, Marcel Hibert, \\ Nicolas Girard* and Dominique Bonnet*
}

\begin{abstract}
Herein, we report an unprecedented, short and diastereo-selective synthesis of newly reported aza-diketopiperazine (aza-DKP) scaffolds starting from amino acids. The strategy is based on a $\mathrm{Rh}(1)$-catalyzed hydroformylative cyclohydrocarbonylation of allyl-substituted azaDKP, followed by a diastereoselective functionalization of the platform. This methodology allows the synthesis of novel bicyclic and tricyclic aza-DKP scaffolds incorporating six- or seven-membered rings, with potential applications in medicinal chemistry.
\end{abstract}

The diketopiperazine (DKP) moiety found in several natural products has been extensively studied in medicinal chemistry. ${ }^{1}$ However, the corresponding aza-DKP platform remains underexplored. ${ }^{2}$ This class of heterocycles can be viewed as a constrained dipeptidomimetic DKP analogue (Fig. 1). As reported for aza-peptides, ${ }^{3}$ the replacement of one $\mathrm{C}_{\alpha}$-stereogenic center by a planar nitrogen atom could have a profound impact on both the chemical and biological properties of DKP and could offer new potential for drug discovery and chemical biology.

Recently, we have described a convenient access to original 2,4,5-trisubstituted-1,2,4-triazine-3,6-diones, both in solution<smiles></smiles>

DKP
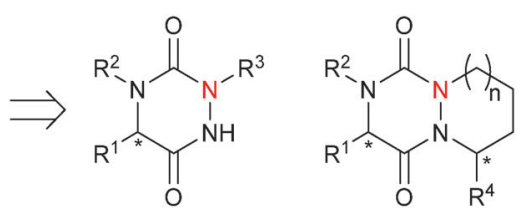

Aza-DKP
Fig. 1 General structure of diketopiperazines (DKP) and aza-diketopiperazines (aza-DKP).

Laboratoire d'Innovation Thérapeutique, UMR7200 CNRS/Université de Strasbourg, Labex Médalis, Faculté de Pharmacie, 74 route du Rhin, 67412 Illkirch, France. E-mail: nicolas.girard@unistra.fr, dominique.bonnet@unistra.fr

$\dagger$ Electronic supplementary information (ESI) available: Detailed experimental procedures and analytical data for all the compounds. Crystal structures of $\mathbf{5 a}, \mathbf{5 i}$, 5k, 6a, 7, trans-isomer of $\mathbf{9}$ and cis-isomers of $\mathbf{6 l}$ and $\mathbf{6 j}$. CCDC 1001769-1001776. For ESI and crystallographic data in CIF or other electronic format see DOI: $10.1039 / \mathrm{c} 4 \mathrm{cc} 03660 \mathrm{c}$

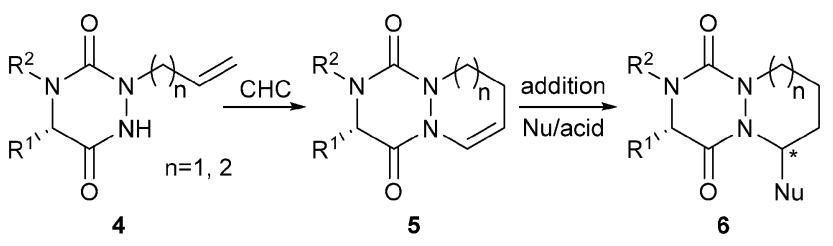

Scheme 1 Strategy towards novel N-heterocyclic aza-DKP scaffolds 6.

and in the solid-phase. ${ }^{2 b}$ In the present work, we report a diversity-oriented, efficient and stereoselective synthesis of novel bicyclic and tricyclic scaffolds 6 derived from aza-DKP. To access such structures, we have explored a strategy based on cyclohydrocarbonylation (CHC) ${ }^{4}$ of allyl aza-DKP 4 , followed by an acid-catalyzed diastereoselective nucleophilic addition on the resulting enamide 5 (Scheme 1). This strategy involves for the first time the catalytic hydroformylation of a newly reported 1,2,4-triazine-3,6-dione system. ${ }^{2 a, b}$ The scope, limitations and diastereoselectivity of the approach have been carefully studied, resulting in the preparation of enantiomerically pure scaffolds with potential applications in medicinal chemistry.

To investigate the applicability of the CHC reaction to azaDKP systems, we initially prepared a set of allyl-substituted precursors $\mathbf{4 a -} \mathbf{g}$ and $\mathbf{4 k}, \mathbf{l}$ according to our previously described procedure. ${ }^{2 b}$ The amino acids were converted into amino esters which were alkylated by reductive amination. The resulting secondary amines $\mathbf{2 a -} \mathbf{g}$ and $\mathbf{2 k}, \mathbf{l}$ as well as the proline derivatives $\mathbf{2 h}-\mathbf{j}$ and $\mathbf{2 m}$ were reacted with bis(trichloromethyl)carbonate (BTC) and allyl or homoallyl $t$-butyl carbazate 1a or $\mathbf{1 b}$, obtained in one step from commercially available $t$-butyl carbazate (see $\mathrm{ESI} \uparrow$ for a detailed procedure). The crude semicarbazides 3a-m were then treated in TFA/water $(95: 5)$ for $1 \mathrm{~h}$, resulting in the consecutive semi-carbazide deprotection and cyclization. This led to allyl derivatives $\mathbf{4 a}-\mathbf{m}$, in $27 \%$ to $77 \%$ yields from amines $\mathbf{2 a}-\mathbf{j}$, the lower yields being obtained with the most sterically hindered $\mathrm{R}^{1}$ and $\mathrm{R}^{2}$ substituents (Table 1 , entries 3 and 4). Noteworthily, the preparation of aza-DKP $4 \mathbf{i}$ and $\mathbf{4 m}$ (from L-hydroxyproline) required hydroxy protection prior to semicarbazide cyclization (Table 1, entries 9 and 12). 
Table 1 CHC-based strategy towards novel bicyclic and tricyclic aza-DKP scaffolds $\mathbf{5 a - m}$

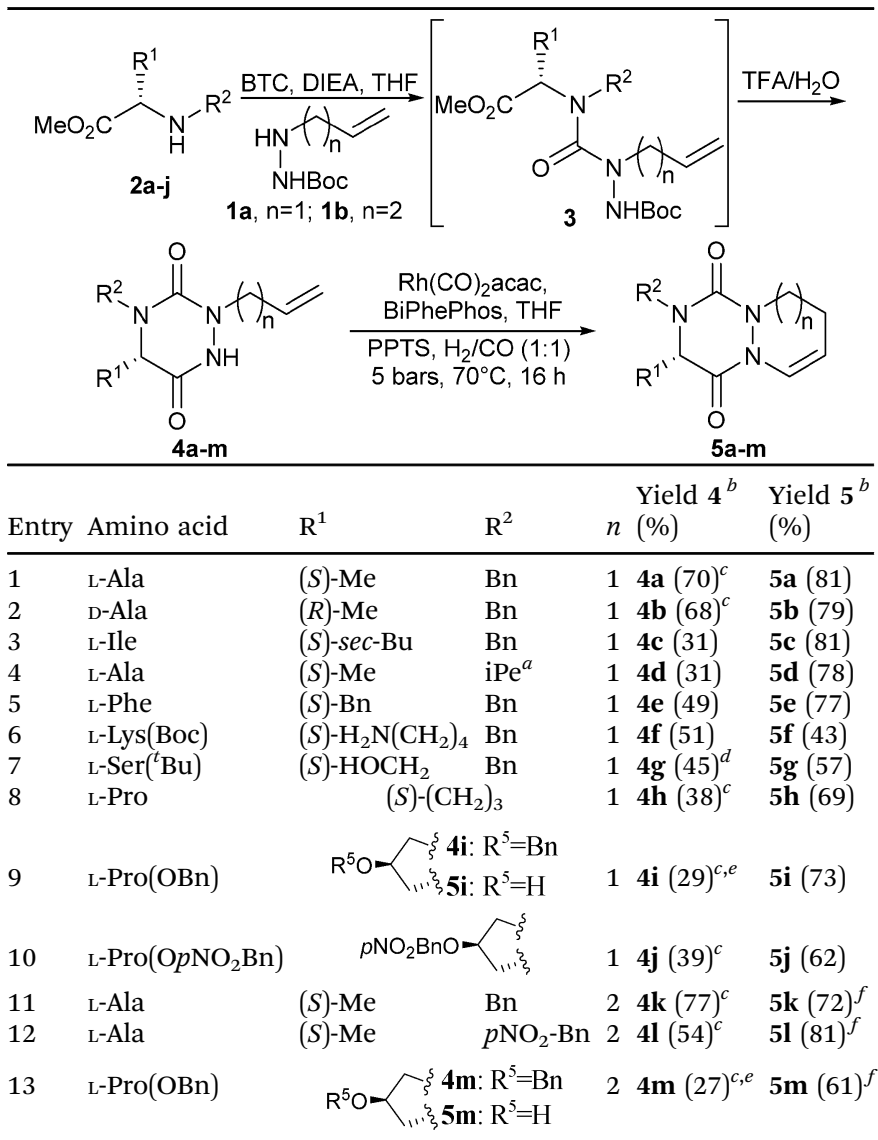

${ }^{a} \mathrm{iPe}=$ isopentyl. ${ }^{b}$ Isolated yields. ${ }^{c}$ Semicarbazide 3 was obtained in THF/ $\mathrm{CH}_{2} \mathrm{Cl}_{2} .{ }^{d}$ Compound $\mathbf{4 g}$ was obtained in TFA/water/triisopropylsilane $(95 / 2.5 / 2.5, \mathrm{v} / \mathrm{v} / \mathrm{v}) .{ }^{e}$ Cleavage of the benzyl protecting group was performed prior to CHC. ${ }^{f}$ CSA instead of PPTS.

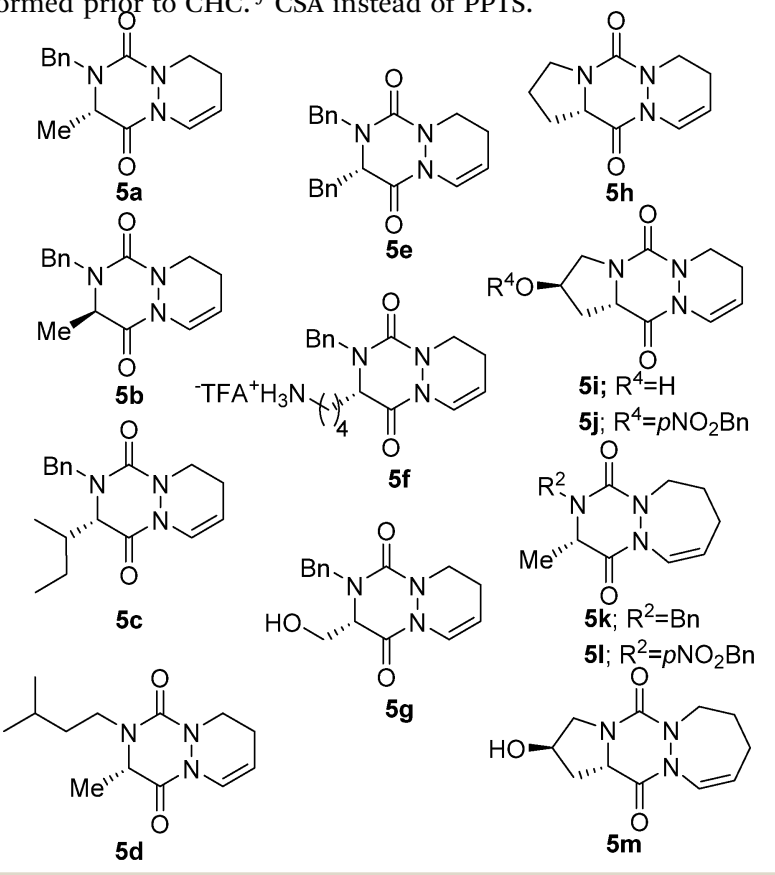

With compounds $\mathbf{4 a - m}$ in hand, we explored the CHC using syngas $\left(\mathrm{H}_{2} / \mathrm{CO}\right)$ in the presence of a $\mathrm{Rh}(\mathrm{I})$ catalyst. ${ }^{5}$ BiPhePhos was selected as a metal chelating agent to ensure the formation of linear rather than branched aldehydes. ${ }^{6}$ All reactions were performed under acid catalysis (pyridinium $p$-toluenesulfonate: PPTS or camphorsulfonic acid: CSA) to promote cyclization, if any, into enamide 5 in the same reactor.

In our first attempt, we were pleased to obtain cyclized compound 5a in an excellent $81 \%$ yield from allyl compound 4a, thus validating the $\mathrm{CHC}$ as a convenient and high yielding method for bicyclic aza-DKP synthesis (Table 1, entry 1).

Next, the scope and limitations of the reaction were evaluated on allylic aza-DKP $\mathbf{4 b}-\mathbf{m}$. In all cases, the expected cyclized compounds 5 were isolated in yields ranging from 43 to $81 \%$ (Table 1), thus demonstrating the efficiency of the method, regardless of the nature of $\mathrm{R}^{1}$ and $\mathrm{R}^{2}$ (Table 1 , entries $3-5$ ) or of the configuration of the starting amino acid (Table 1, entry 2). Noteworthily, CHC still occurred in reasonable yields with compounds $\mathbf{4 f}$ and $\mathbf{4 g}$ encompassing nucleophile groups at $\mathrm{R}^{3}$, which could possibly compete as a ligand for the metal (Table 1, entries 6 and 7 ). ${ }^{7}$

Interestingly, $\mathrm{CHC}$ also gave access to tricyclic L-prolinebased aza-DKP $5 \mathbf{h}, \mathbf{5 i}$ and $\mathbf{5 j}$ in good $69 \%, 73 \%$ and $62 \%$ yields, respectively (Table 1 , entries $8-10$ ). This scaffold is particularly appealing for medicinal chemistry as the corresponding DKP is embedded in the core of several natural product classes used in targeted cancer therapy. ${ }^{8}$

These promising results for the synthesis of six-membered rings prompted us to evaluate $\mathrm{CHC}$ as an entry to aza-DKP fused to a seven-membered ring. Thus, with homoallylic derivative $\mathbf{4 k}$, the $\mathrm{CHC}$ reaction proceeded smoothly and $\mathbf{5 k}$ was obtained in moderate yield (34\%). Then, we switched from PPTS to the more acidic CSA, which drives the reaction to completion and dramatically improves the yield (72\%). This optimized procedure was also applied to the synthesis of tricyclic L-hydroxyproline-based aza-DPK $\mathbf{5 m}$ obtained in $61 \%$ yield.

With all these novel structures in hand, we decided to investigate the functionalization of the diaza-cyclohexene and diaza-cycloheptene rings in order to extend the molecular diversity of these novel scaffolds. A first experiment was carried out by subjecting compound 5a to a CSA acid-catalyzed addition of $\mathrm{MeOH}$ which led to hemiaminal 6a with a high $86 \%$ yield and a good diastereoisomeric ratio (dr) of 93:7 (Table 2, entry 1). The major isomer was readily isolated by preparative HPLC and was shown to be the C9-C2 trans-isomer by X-ray diffraction analysis (Fig. 2). This result combined with the axial position of the methoxy group indicate that the nucleophilic attack of the acyl iminium intermediate is likely under stereoelectronic control. ${ }^{9}$ The out-of-plane substituents associated with the presence of stereocenters make the aza-DKP scaffold a promising platform to increase receptor-ligand interactions and to develop potentially active and selective compounds. ${ }^{10}$

The diastereoselective addition reaction was then extended to various enamides. As shown in Table 2, the expected compound was obtained whatever the absolute configuration at $\mathrm{C}_{\alpha}$ (Table 2, entry 2). The steric hindrance at $\mathrm{R}^{2}$ was found to impact the selectivity (Table 2 , entry 4 ). In contrast, when a 
Table 2 Diastereoselective acid-catalyzed addition of $\mathrm{MeOH}$ on enamide $\mathbf{5}$

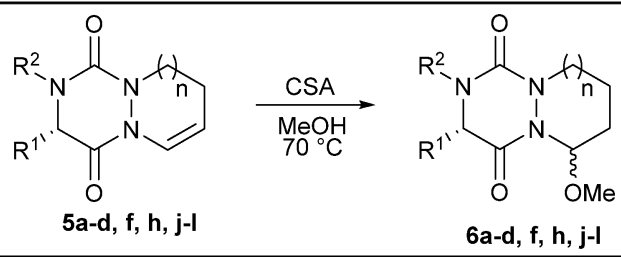

\begin{tabular}{|c|c|c|c|c|c|}
\hline Entry & $\mathrm{R}^{1}$ & $\mathrm{R}^{2}$ & $n$ & Yield $^{b}(\%)$ & $\operatorname{dr}(\text { trans } / \text { cis })^{c}$ \\
\hline 1 & $(S)$-Me & $\mathrm{Bn}$ & 1 & 6a (86) & $93: 7$ \\
\hline 2 & $(R)-\mathrm{Me}$ & $\mathrm{Bn}$ & 1 & $6 \mathbf{b}(83)$ & $92: 8$ \\
\hline 3 & $(S)-s e c-\mathrm{Bu}$ & $\mathrm{Bn}$ & 1 & $6 c(65)$ & $>99: 1$ \\
\hline 4 & $(S)$-Me & $\mathrm{iPe}^{a}$ & 1 & 6d $(74)$ & $97: 3$ \\
\hline 5 & $(S)-\mathrm{H}_{2} \mathrm{~N}\left(\mathrm{CH}_{2}\right)_{4}$ & $\mathrm{Bn}$ & 1 & $6 \mathbf{f}(61)$ & $96: 4$ \\
\hline 6 & $(S)-(\mathrm{CI}$ & & 1 & $6 h(65)$ & $4: 96$ \\
\hline 7 & & & 1 & $\mathbf{6 j}(59)$ & $4: 96$ \\
\hline 8 & $(S)$-Me & $\mathrm{Bn}$ & 2 & $6 \mathbf{k}(62)$ & $37: 63$ \\
\hline 9 & $(S)$-Me & $p \mathrm{NO}_{2} \mathrm{Bn}$ & 2 & $61(55)$ & $37: 63$ \\
\hline
\end{tabular}

${ }^{a}$ iPe $=$ isopentyl. ${ }^{b}$ Isolated yields. ${ }^{c}$ Diastereomeric ratio was determined by ${ }^{1} \mathrm{H}$ NMR or HPLC analysis of the crude reaction mixtures.

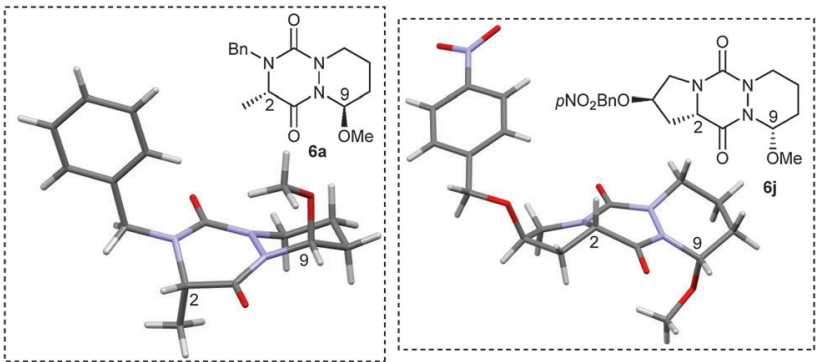

Fig. 2 X-ray structures of compounds $\mathbf{6 a}$ and $\mathbf{6 j}$.

hindered group was introduced at $\mathrm{R}^{1}$, only one diastereomer was detected by ${ }^{1} \mathrm{H}$ NMR and HPLC analyses of the crude material (Table 2, entry 3). The diastereoselective addition was also found compatible with the presence of a nucleophilic primary amine at $\mathrm{R}^{1}$ (Table 2, entry 5). Interestingly, when the addition was performed on tricyclic proline derivatives $\mathbf{5 h}$ and $5 \mathbf{j}$ (Table 2, entries 6 and 7), desired hemiaminals $\mathbf{6 h}$ and $\mathbf{6 j}$ were also obtained in good yields (65\% and $59 \%$, respectively) but with an inverted dr in favor of the cis-isomer (4:96), as demonstrated by X-ray diffraction analysis of $\mathbf{6 j}$ (Fig. 2). The inversion of $\mathrm{dr}$ for proline-based substrates compared to other amino acids was previously reported for the 2,5-diketopiperazine system. ${ }^{11,12}$ Finally, the addition performed on seven-membered rings $5 \mathbf{k}$ and $\mathbf{5 l}$ led to the corresponding
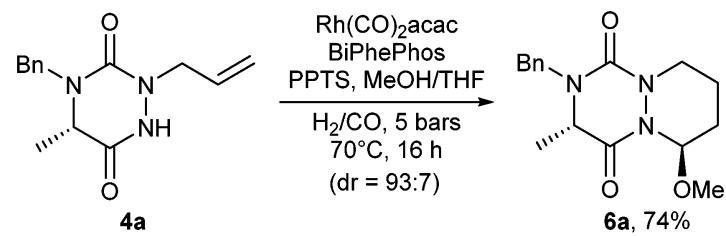

Scheme 2 Domino cyclohydrocarbonylation/addition reaction.

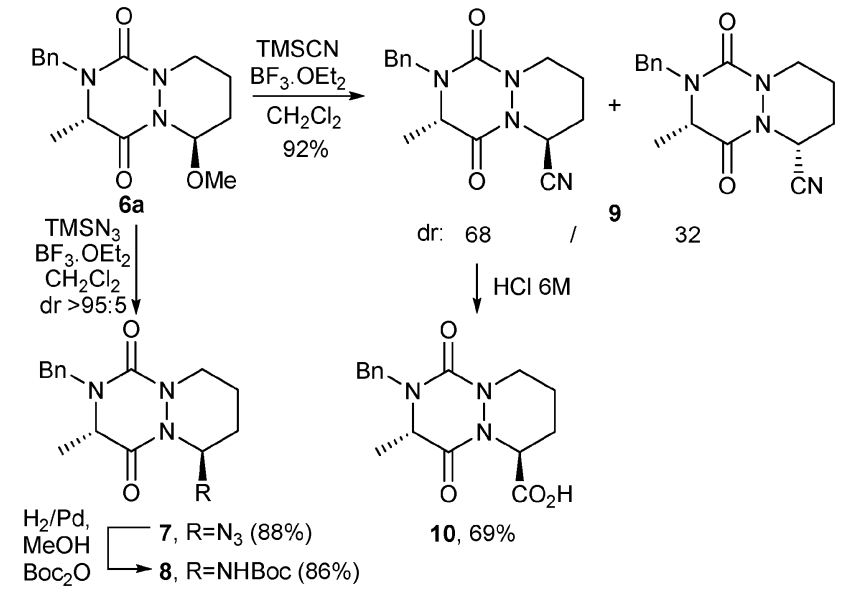

Scheme 3 Diastereoselective functionalization of aza-DKP $\mathbf{6 a}$.

hemiaminals $\mathbf{6 k}$ and $\mathbf{6 l}$ in still good yields (62 and 55\%, respectively) but with a lower $\mathrm{dr}(37: 63)$, likely due to greater flexibility of the seven-membered ring. ${ }^{13}$ As aforementioned for $\mathbf{6 h}$ and $\mathbf{6 j}$, the X-ray diffraction analysis of $\mathbf{6 1}$ revealed that the major isomer was the C9-C2 cis-isomer.

Looking for a further improvement in the access to novel aza-DKP platforms, a domino CHC/acid-catalyzed $\mathrm{MeOH}$ addition sequence was envisaged (Scheme 2). ${ }^{14}$ To this end, $N$-allyl substituted triazinedione $\mathbf{4 a}$ was submitted to a CHC reaction in the presence of PPTS in $\mathrm{MeOH} / \mathrm{THF}(10: 1)$ and led to compound $6 \mathbf{a}$ in $74 \%$ yield and a good stereoselectivity $(93: 7)$. Thus, compound $\mathbf{6 a}$ is readily attainable in a threestep process only from simple $N$-benzyl amino ester $2 \mathrm{a}$ in a $52 \%$ overall yield. This result highlights the efficiency of our strategy to provide a rapid access to novel N-heterocyclic scaffolds.

Finally, to further enlarge the molecular diversity of novel aza-DKP platforms and access to diversity-oriented chemical libraries, we envisaged the incorporation at C9 of functional groups able to react with commercially available building blocks. Hence, trans-isomer $\mathbf{6 a}$ was reacted either with $\mathrm{TMSN}_{3}$ or with TMSCN, both in the presence of $\mathrm{BF}_{3} \cdot \mathrm{OEt}_{2}$ (Scheme 3$)^{15}$ Thus, azide 7 was obtained in good yield (88\%) and $\mathrm{dr}(>95: 5)$. Nitrile 9 was also isolated in excellent yield (92\%) but with a lower $\mathrm{dr}(68: 32)$. Again, for both compounds, the major isomer was shown to be the C9-C2 trans-isomer (X-ray structure analysis, ESI $\dagger$ ).

Besides, hydrolysis of the major isomer under acidic conditions led to carboxylic acid 10, able to react with amino building-blocks. Azide 7 was reduced with $\mathrm{H}_{2} / \mathrm{Pd}$ in the presence of di-tert-butyl dicarbonate to provide $t$ Boc-protected compound $8(86 \%)$. To further extend the chemical diversity of aza-diketopiperazines, compound 7 could also be engaged in $\mathrm{Cu}(\mathrm{I})$-catalyzed azide-alkyne cycloaddition reactions. ${ }^{16}$

Starting from the amino acid pool, we have developed a diastereoselective approach for the preparation of a diverse range of N-heterocyclic scaffolds derived from aza-DKP. Indeed, this rapid and flexible method enables the efficient conversion of $N$-allyl substituted aza-DKP into newly reported bicyclic or tricyclic scaffolds containing six- or seven-membered rings by a 
domino CHC/addition sequence. A subsequent substitution at C-9 of the aza-DKP allows the diastereoselective incorporation of cyano and azido groups readily amenable, respectively, to amino or carboxylic functions which paves the way to the preparation of diversity-oriented libraries.

This work was supported by the Centre National de la Recherche Scientifique, the Université de Strasbourg (UDS) and the LABEX Medalis (ANR-10-LABX-0034). Dr Denis Heissler is kindly acknowledged for helpful discussions and for his comments on the manuscript. We are grateful to Cyril Antheaume and Barbara Schaeffer for NMR experiments (Service Commun d'Analyse, UDS).

\section{Notes and references}

1 For recent reviews on DKP, see: (a) C. Prasad, Peptides, 1995, 16, 151-164; (b) M. B. Martins and I. Carvalho, Tetrahedron, 2007, 63, 9923-9932; (c) J. F. Gonzalez, I. Ortin, E. de la Cuesta and J. C. Menendez, Chem. Soc. Rev., 2012, 41, 6902-6915; (d) A. D. Borthwick, Chem. Rev., 2012, 112, 3641-3716.

2 (a) C. B. Bourguet, C. Proulx, S. Klocek, D. Sabatino and W. D. Lubell, J. Pept. Sci., 2010, 16, 284-296; (b) D. Bonnet, J. F. Margathe, S. Radford, E. Pflimlin, S. Riche, P. Doman, M. Hibert and A. Ganesan, ACS Comb. Sci., 2012, 14, 323-334.

3 (a) A. Zega, Curr. Med. Chem., 2005, 12, 589-597; (b) H. J. Lee, I. A. Ahn, S. Ro, K. H. Choi, Y. S. Choi and K. B. Lee, J. Pept. Res., 2000, 56, 35-46.
4 (a) I. Ojima, M. Tzamarioudaki and M. Eguchi, J. Org. Chem., 1995, 60, 7078-7079. For reviews on CHC, see: $(b)$ B. Breit and W. Seiche, Synthesis, 2001, 1-36; (c) W.-H. Chiou, S.-Y. Lee and I. Ojima, Can. J. Chem., 2005, 83, 681-692; (d) G. Varchi and I. Ojima, Curr. Org. Chem., 2006, 10, 1341-1362.

5 E. Airiau, T. Spangenberg, N. Girard, A. Schoenfelder, J. Salvadori, M. Taddei and A. Mann, Chem. - Eur. J., 2008, 14, 10938-10948.

6 G. D. Cuny and S. L. Buchwald, J. Am. Chem. Soc., 1993, 115, 2066-2068.

7 L. L. W. Cheung, G. Vasapollo and H. Alper, Adv. Synth. Catal., 2012, 354, 2019-2022.

8 S. K. Rabindran, D. D. Ross, L. A. Doyle, W. Yang and L. M. Greenberger, Cancer Res., 2000, 60, 47-50.

9 P. Deslongchamps, Stereoelectronic Effects in Organic Chemistry, Pergamon, New York, 1983, ch. 6.

10 F. Lovering, J. Bikker and C. Humblet, J. Med. Chem., 2009, 52, 6752-6756.

11 A. Siwicka, K. Wojtasiewicz, B. Rosiek, A. Leniewski, J. K. Maurin and Z. Czarnocki, Tetrahedron: Asymmetry, 2005, 16, 975-993.

12 J. Baek, S. Y. Kang, C. Im and Y. S. Park, Eur. J. Org. Chem., 2014, $2780-2789$.

13 (a) N. Zill, A. Schoenfelder, N. Girard, M. Taddei and A. Mann, J. Org. Chem., 2012, 77, 2246-2253; (b) A. J. Pearson and Y. Kwak, Tetrahedron Lett., 2005, 46, 3407-3410.

14 E. Airiau, N. Girard, M. Pizzeti, J. Salvadori, M. Taddei and A. Mann, J. Org. Chem., 2010, 75, 8670-8673.

15 S. Röper, R. Wartchow and H. M. R. Hoffmann, Org. Lett., 2002, 4, 3179-3182.

16 (a) H. C. Kolb, M. G. Finn and K. B. Sharpless, Angew. Chem., Int. Ed., 2001, 40, 2004-2021; (b) M. Meldal and C. W. Tornøe, Chem. Rev., 2008, 108, 2952-3015; (c) P. Thirumurugan, D. Matosiuk and K. Jozwiak, Chem. Rev., 2013, 113, 4905-4979. 